\title{
Prevalence, Comorbidity and Investigation of Anemia in the Primary Care Office
}

\author{
Shivani Jatin Gandhi ${ }^{\mathrm{a}}$, Iris Hagans ${ }^{\mathrm{a}}$, Karim Nathan ${ }^{\mathrm{a}}$, Krystal Hunter ${ }^{\mathrm{b}}$, \\ Satyajeet Roy, c
}

\begin{abstract}
Background: Anemia has a myriad of causes and its prevalence is growing. Anemia is associated with increased all-cause hospitalization and mortality in community-dwelling individuals above age 65 years. Our aim was to determine the prevalence and severity of anemia in adult patients in our primary care office and to determine the relationship between anemia and medical comorbidities.
\end{abstract}

Methods: Electronic medical records of 499 adult patients in our suburban internal medicine office were reviewed who had had at least one hemoglobin value and did not undergo moderate to high-risk surgery in the preceding 30 days.

Results: About one-fifth (21.1\%) of the patients had anemia. The mean age of patients with anemia was 62.6 years. Among all patients with anemia, $20.3 \%$ were males and $79.6 \%$ were females. Of these patients, $60.1 \%$ had mild anemia (hemoglobin $11-12.9 \mathrm{~g} / \mathrm{dL}$ ) and $39.8 \%$ had moderate anemia (hemoglobin $8-10.9 \mathrm{~g} / \mathrm{dL}$ ). For every year of increase in age, there was $1.8 \%$ increased odds of having anemia. African-American race had 5.2 times greater odds of having anemia than the Caucasian race. Hispanic race had 3.2 times greater odds of having anemia compared to the Caucasian race. $\mathrm{Pa}-$ tients with anemia had a greater average number of comorbidities compared to patients without anemia (1.74 and 0.96, respectively; $\mathrm{P}<0.05)$. There was a statistically greater percentage of patients with essential hypertension, hypothyroidism, chronic kidney disease, malignancy, rheumatologic disease, congestive heart failure, and coronary artery disease in the anemic population as compared to the non-anemic population. Of the patients, $41 \%$ with mild anemia and $62 \%$ with moderate anemia underwent additional diagnostic studies. Of the patients, $14.8 \%$ had resolution of anemia without therapy in 1 year, $15.7 \%$ were on iron replacement therapy, and $6.5 \%$ were on

Manuscript submitted October 6, 2017, accepted October 23, 2017

aDepartment of Medicine, Cooper University Hospital, Cooper Medical School of Rowan University, Camden, NJ, USA

${ }^{b}$ Cooper Research Institute, Cooper Medical School of Rowan University, Camden, NJ, USA

${ }^{\mathrm{c} C o r r e s p o n d i n g ~ A u t h o r: ~ S a t y a j e e t ~ R o y, ~ D e p a r t m e n t ~ o f ~ M e d i c i n e, ~ C o o p e r ~ U n i-~}$ versity Hospital, Cooper Medical School of Rowan University, 1103 North Kings Highway, Suite 203, Cherry Hill, NJ 08034, USA.

Email: roy-satyajeet@cooperhealth.edu

doi: https://doi.org/10.14740/jocmr3221w cobalamin therapy. No specific etiology of anemia was found in $24 \%$ of patients.

Conclusion: A higher prevalence of anemia was associated with advancing age, African-American and Hispanic ethnicity, and comorbidities, such as essential hypertension, hypothyroidism, chronic kidney disease, malignancy, rheumatologic disease, congestive heart failure, and coronary artery disease. It is important to be aware of the demographic factors and their relationship to anemia in primary care.

Keywords: Anemia; Primary care; Racial differences in anemia

\section{Introduction}

Anemia is a broad entity and often a result of underlying disease. There are a myriad of factors which can contribute to anemia, including medications, nutritional deficiencies, chronic inflammatory conditions, malignancy, renal dysfunction, bone marrow disorders, and inherent disorders in red blood cells (RBCs) or hemoglobin production. Recent studies have suggested that anemia is quite common among adults, and may have a deleterious impact on overall health [1-4].

Many studies have shown a relationship between anemia and aging [1-4] and ethnicity [1]. Other studies have investigated the effects of anemia on chronic medical conditions that affect our adult population, including congestive heart failure (CHF), chronic obstructive pulmonary disease (COPD), type 2 diabetes mellitus (T2DM), chronic kidney disease (CKD), and coronary artery disease. Anemia is shown to be associated with increased risk of hospitalization in the elderly [5] as well as morbidity and resource utilization in patients with CHF [6-8], COPD [9], diabetes mellitus with co-existing CKD [10], and patients undergoing coronary artery bypass grafting $(\mathrm{CABG})$ [11-13].

Since the prevalence of anemia is growing, it has become ever-important to search for the underlying cause of anemia in primary care. In the outpatient setting, anemia is commonly diagnosed with a complete blood count (CBC) assay, which provides the hemoglobin value, hematocrit, and mean corpuscular volume (MCV). From this information, physicians can order subsequent testing to investigate the pathogenesis of the 
anemia. Many algorithms exist for the investigation of anemia in the outpatient setting, most of which are guided by the MCV [8].

Many studies have shown that the most common causes of anemia in patients greater than age 65 include anemia due to nutritional disease, CKD, and chronic inflammation [1-4]. However, the cause of anemia remains unexplained in about one-third of elderly patients with anemia [1-4]. To our knowledge, there has been no study directed towards the frequency that providers conduct a thorough investigation to establish a cause for anemia in their patient population.

We hypothesized that the prevalence and severity of anemia in our patient population would increase with increasing age and the presence of other medical comorbidities. Our primary objective was to determine the prevalence and severity of anemia in adult patients within our primary care office, and determine if there was a relationship between anemia and the presence of medical comorbidities. Our secondary objective was to determine if there was a statistical difference in the number of patients with anemia in which at least one subsequent diagnostic test was performed in order to establish a cause of the anemia, based on the severity of anemia and the comorbidities.

\section{Materials and Methods}

\section{Study selection}

Our study was a retrospective review of the electronic medical records of adult patients who had at least one hemoglobin level available for review. This study was reviewed and approved by the Institutional Review Board of the Cooper Health System, Camden, New Jersey, USA.

Permission was granted to use materials that were collected solely for research study purposes as per the Health Insurance Portability and Accountability Act (HIPAA) requirements, and the informed consent waivers were granted by the Institutional Review Board.

We selected 499 adult patients aged 18 years or older who had a documentation of hemoglobin level in the electronic medical record and an office visit between July 2014 and June 2015. We excluded patients if the office visit was not within July 2014 and June 2015 or if the hemoglobin value was not available. Additionally, we also excluded patients with a moderate or high risk surgery in the past 30 days, or if the hemoglobin level was obtained in an acute care setting.

\section{Data collection}

We collected the following data on each patient: age; gender; race (African American, Hispanic, Caucasian, Asian, and other); family or personal history of anemia (sickle cell, thalassemia, RBC membrane defect, other, and none); smoking history (current smoker and former smoker); alcohol use; body mass index (BMI); associated medical conditions including diabetes mellitus, hypertension, hypothyroidism, CKD, malignancy, rheumatologic disease, liver disease, CHF, COPD, and coronary artery disease (CAD); hemoglobin level ( $>14 \mathrm{~g} / \mathrm{dL}$, $11-13.9 \mathrm{~g} / \mathrm{dL}, 8-10.9 \mathrm{~g} / \mathrm{dL}$, and $<8.0 \mathrm{~g} / \mathrm{dL})$; whether further diagnostic testing was performed (including serum iron, total iron binding capacity (TIBC), ferritin, folic acid, cobalamin, fecal occult blood test, protein electrophoresis, or reticulocyte count); and treatment for anemia (including iron, cyanocobalamin, folic acid, erythropoiesis stimulating agents, or no treatment).

\section{Statistical analysis}

We entered the patient data in a Microsoft Excel (2013, Redmond, Washington, USA) spreadsheet and analyzed them using SPSS (Statistical Package for the Social Sciences, version 15.01, IBM, Armonk, New York, USA). A sample size of greater than 300 patients was selected based on the estimated number of patients with a hemoglobin level in the electronic medical record. An independent $t$-test was used to compare the mean age between the anemia and non-anemia groups and one-way ANOVA was used to compare the mean age between the anemia severity groups (no anemia, mild anemia and moderate anemia). The Mann-Whitney U test was used to compare the mean rank number of comorbidities between the anemia and no anemia groups, while the Kruskall-Wallis test was used to compare the mean rank between the severities of anemia in our patient sample. Chi-square tests were used to determine the relationship between ethnicity and individual comorbidities with the prevalence and severity of anemia.

Among the ethnic groups, Fisher's exact test was used to compare the patients with anemia and patients without anemia. A logistic regression was used to determine the odd ratios for having anemia with respect to age, gender, ethnicity, and the presence of certain comorbid conditions.

\section{Results}

A total of 499 patients were included in the study. Of the patients that were included in the study, $40.5 \%$ were males and $59.5 \%$ were females. Caucasians were the largest ethnic group within our patient population $(73.3 \%)$, followed by African-Americans (10\%), Hispanics (8.6\%), Asians $(2.4 \%)$ and other ethnicities (4.8\%). Non-smokers constituted $60.3 \%$ of patients, while $11.6 \%$ of patients were active smokers, and $28.1 \%$ of patients were former smokers. Moreover, $61.7 \%$ had active alcohol use, but the amount was not specified (Table 1). The majority of our patients had no family history or personal history of inherited anemia (99.1\% and 90.7\%, respectively) (Table 1).

Among all patients included in the study, $77.9 \%$ of patients did not have anemia, while $22.1 \%$ of patients had mild or moderate anemia. Of the patients with anemia, $60 \%$ of patients had mild anemia (defined as hemoglobin $11-1.9 \mathrm{~g} / \mathrm{dL}$ in females, hemoglobin $11-12.9 \mathrm{~g} / \mathrm{dL}$ in males), and $40 \%$ of 
Table 1. Baseline Demographics of All Patients $(N=499)$

\begin{tabular}{|c|c|}
\hline Variable & Percentage of patients \\
\hline \multicolumn{2}{|l|}{ Male } \\
\hline Female & 59.5 \\
\hline \multicolumn{2}{|l|}{ Race } \\
\hline Caucasian & 73.3 \\
\hline African-American & 10.6 \\
\hline Hispanic & 8.6 \\
\hline Asian & 2.4 \\
\hline Other & 5.1 \\
\hline \multicolumn{2}{|l|}{ Social history } \\
\hline Current smoker & 11.6 \\
\hline Former smoker & 28.1 \\
\hline Never smoker & 60.3 \\
\hline Active alcohol use & 61.7 \\
\hline \multicolumn{2}{|l|}{ Family history of hereditary anemia } \\
\hline Sickle cell anemia & 0.2 \\
\hline Thalassemia & 0 \\
\hline RBC membrane defect & 0 \\
\hline Other & 0.6 \\
\hline No family history of anemia & 99.1 \\
\hline \multicolumn{2}{|l|}{ Personal history of anemia } \\
\hline Sickle cell & 0.2 \\
\hline Thalassemia & 0.4 \\
\hline RBC membrane defect & 0 \\
\hline No personal history of anemia & 90.7 \\
\hline Other & 8.4 \\
\hline \multicolumn{2}{|l|}{ Comorbidities } \\
\hline Diabetes mellitus & 17.2 \\
\hline Essential hypertension & 45.3 \\
\hline Hypothyroidism & 12.8 \\
\hline Chronic kidney disease & 4.6 \\
\hline Malignancy & 10 \\
\hline Rheumatologic disease & 3.8 \\
\hline Chronic liver disease & 4 \\
\hline Congestive heart failure & 2.8 \\
\hline Coronary artery disease & 10.2 \\
\hline Chronic obstructive pulmonary disease & 3 \\
\hline Average age & 56.3 years \\
\hline Average BMI & $29.4 \mathrm{~kg} / \mathrm{m}^{2}$ \\
\hline
\end{tabular}

patients had moderate anemia (defined as hemoglobin 8 - 10.9 $\mathrm{g} / \mathrm{dL}$ in females or males). There were no patients with severe anemia, as defined by hemoglobin level of less than $8 \mathrm{~g} / \mathrm{dL}$ (Tables 2-5).

Although the total number of patients in the study was
499, there were two patients who had missing anemia data. Hence, Table 1 reports a descriptive analysis of all 499 patients with no stratification, whereas Tables 2 and 3 report comparisons between anemia and non-anemia groups in the remaining 497 patients. 
Table 2. Demographic Comparison of Patients Without Anemia to Patients With Anemia

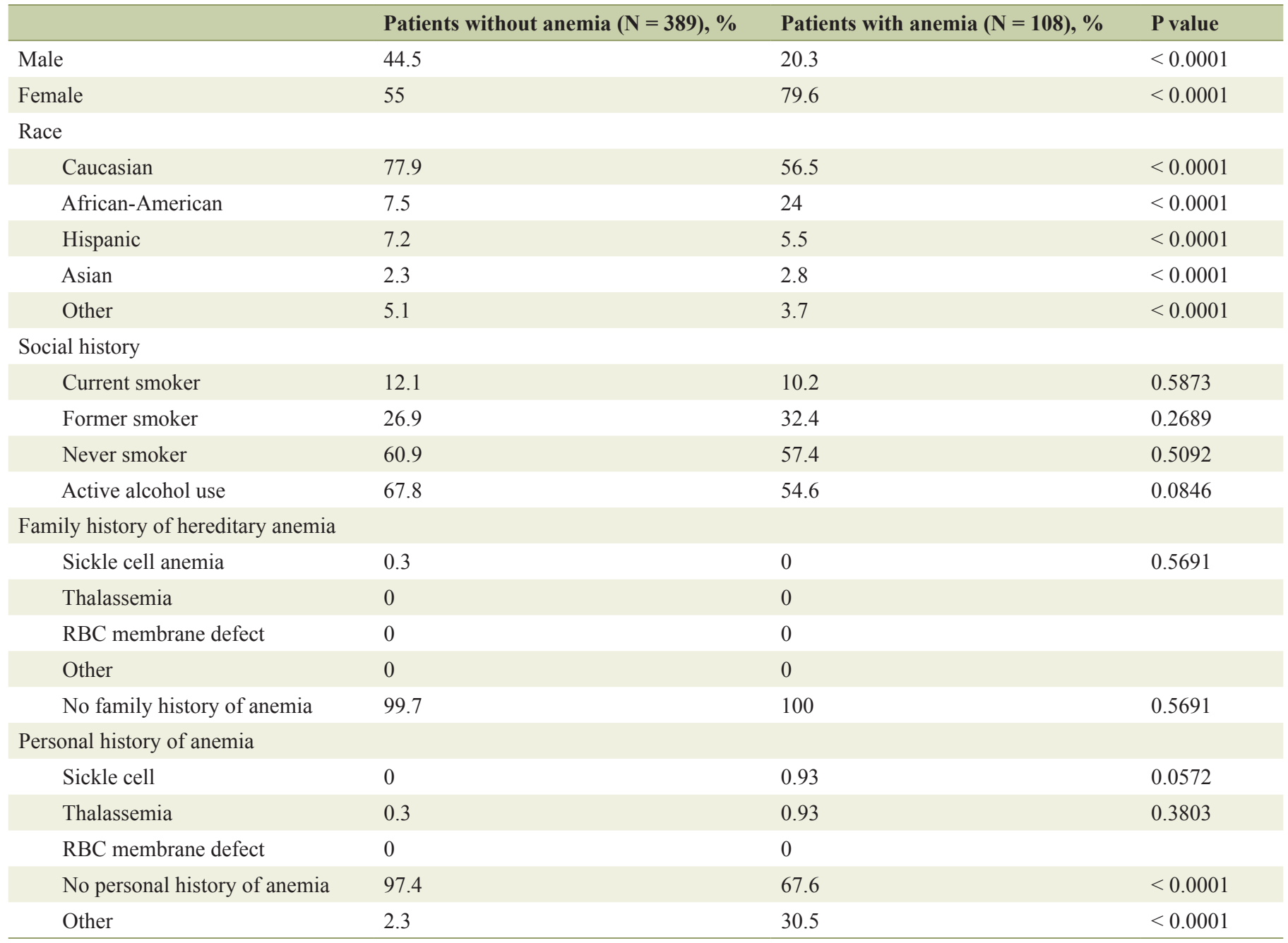

Table 3. Comparison of Comorbidities in Patients Without Anemia to Patients With Anemia

\begin{tabular}{llll}
\hline Comorbidities & Patients without anemia $(\mathbf{N}=\mathbf{3 8 9}), \boldsymbol{\%}$ & Patients with anemia $(\mathbf{N}=\mathbf{1 0 8}), \mathbf{\%}$ & $\mathbf{P}$ value \\
\hline Diabetes mellitus & 16.4 & 19.4 & 0.4651 \\
Essential hypertension & 41.1 & 59.3 & 0.0008 \\
Hypothyroidism & 10.5 & 21.3 & 0.003 \\
Chronic kidney disease & 2.3 & 11.1 & 0.0001 \\
Malignancy & 7.7 & 18.5 & 0.001 \\
Rheumatologic disease & 2.8 & 7.4 & 0.0269 \\
Chronic liver disease & 3.3 & 6.5 \\
Congestive heart failure & 1.8 & 6.5 \\
Coronary artery disease & 7.9 & 18.5 & 0.1355 \\
Chronic obstructive pulmonary disease & 2.3 & 5.6 & 0.0091 \\
Average age & $54.5 \mathrm{years}$ & $62.6 \mathrm{years}$ & 0.0014 \\
Average BMI & $29 \mathrm{~kg} / \mathrm{m}^{2}$ & $30.5 \mathrm{~kg} / \mathrm{m}^{2}$ & 0.08 \\
Average number of comorbid illnesses & 0.96 & 1.74 \\
\hline
\end{tabular}


Table 4. Comparison of Patients With Mild Anemia to Patients With Moderate Anemia

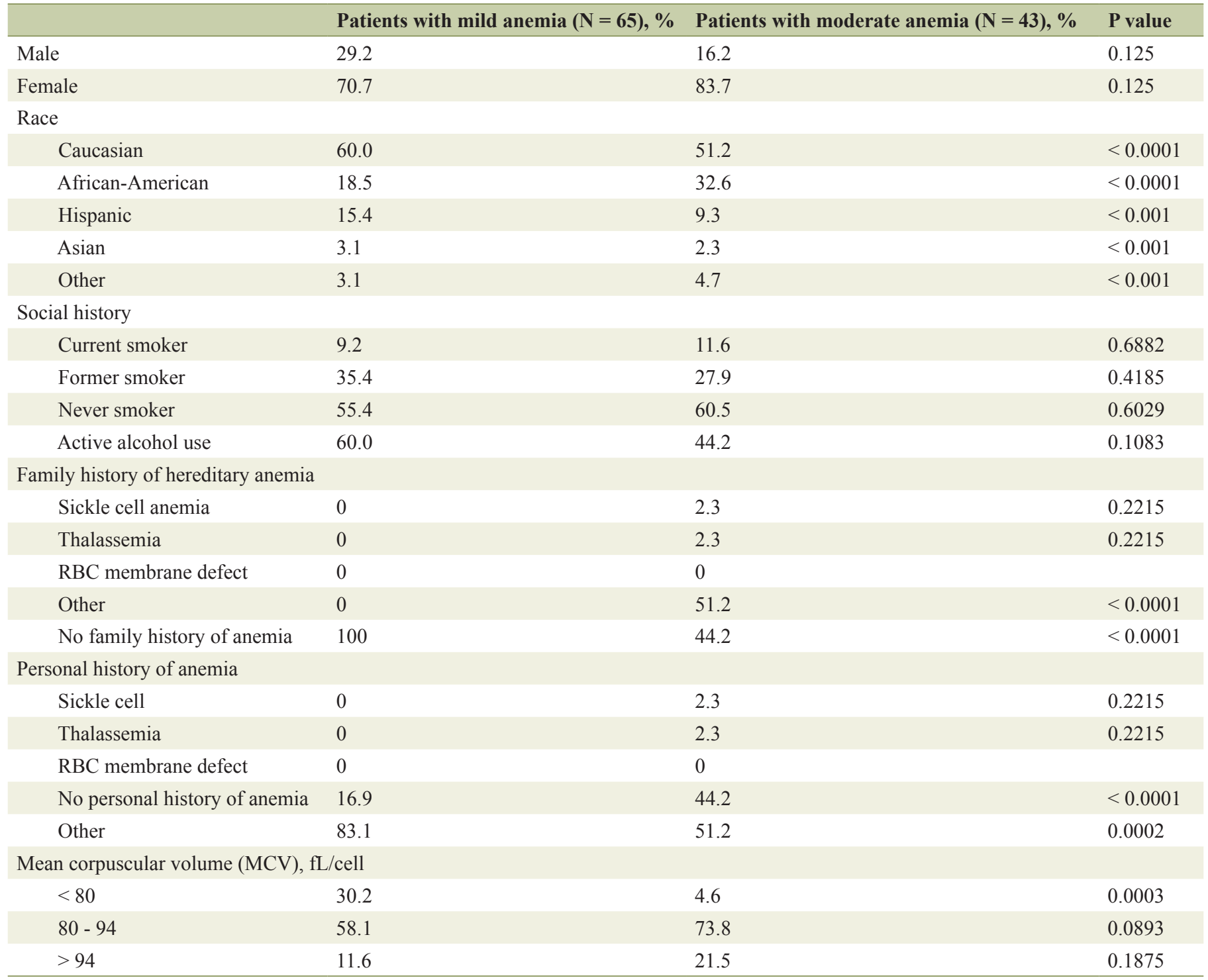

When comparing patients without anemia to patients with anemia, there were several differences between each group that had statistical significance. The average age of patients with anemia was 8.1 years greater than the average age of patients without anemia (Table 3). Further analysis of the age groups showed that there was an increasing prevalence of anemia with increasing age (Fig. 1). For every year of increase in age, there was $1.8 \%$ increased odds of having anemia. Also, there was a greater percentage of females in the anemia group as compared to the non-anemia group $(79.6 \%$ compared to $55 \%$, respectively) (Fig. 2).

In regard to ethnicity, the percentage of African-Americans with anemia was greater than three times the percentage of African-Americans without anemia. In addition, the African-American race had 5.2 times greater odds of having anemia than the Caucasian race, while the Hispanic race had 3.2 times greater odds of having anemia compared to the Cau- casian race (Figs. 3 and 4).

In regard to history and comorbidities, there was a statistically greater percentage of patients with essential hypertension, hypothyroidism, CKD, malignancy, rheumatologic disease, CHF, and coronary artery disease in the anemia group as compared to the non-anemia group (Table 3, Fig. $5)$. Furthermore, patients with anemia had a greater average number of comorbid illnesses as compared to patients without anemia (1.74 and 0.96 , respectively), and this difference was found to be statistically significant (Tables 2 and 3). The components of the social history including smoking, alcohol use, and BMI were not found to be statistically significant between the anemia and non-anemia groups (Tables 2 and 3).

When comparing patients with mild anemia and moderate anemia, there was again a statistically significant difference in African-Americans with moderate anemia compared 
Table 5. Comparison of Patients With Mild Anemia to Patients With Moderate Anemia

\begin{tabular}{llll}
\hline Comorbidities & Patients with mild anemia $(\mathbf{N}=\mathbf{6 5}), \mathbf{\%}$ & Patients with moderate anemia $(\mathbf{N}=\mathbf{4 3}), \mathbf{\%}$ & P value \\
\hline Diabetes mellitus & 20 & 18.6 & 0.8578 \\
Essential hypertension & 61.5 & 55.8 & 0.557 \\
Hypothyroidism & 20 & 23.3 & 0.6877 \\
Chronic kidney disease & 9.2 & 11.6 & 0.6851 \\
Malignancy & 20 & 16.2 & 0.6201 \\
Rheumatologic disease & 6.15 & 9.3 & 0.5424 \\
Chronic liver disease & 6.15 & 6.9 & 0.866 \\
Congestive heart failure & 6.15 & 4.7 & 18.6 \\
Coronary artery disease & 16.9 & 6.9 & 0.7401 \\
Chronic obstructive pulmonary disease & 4.6 & $59 \mathrm{years}$ & 0.8211 \\
Average age & $64.8 \mathrm{years}$ & $31.9 \mathrm{~kg} / \mathrm{m}^{2}$ & 0.6 \\
Average BMI & $29.7 \mathrm{~kg} / \mathrm{m}^{2}$ & 1.72 & 0.1127 \\
Average number of comorbid illnesses & 1.76 & 0.186 & 0.8799 \\
\hline
\end{tabular}

to African-Americans with mild anemia (32.6\% and $18.5 \%$, respectively). There were no statistical differences between age, BMI, social history, presence and average number of comorbid illnesses (diabetes, essential hypertension, hypothyroidism, CKD, malignancy, rheumatologic disease, chronic liver disease, $\mathrm{CHF}$, coronary artery disease, or COPD). A greater percentage of patients with mild anemia were found to have microcytosis ( $\mathrm{MCV}<80 \mathrm{fL} /$ cell) as compared to patients with moderate anemia $(30.2 \%$ compared to $4.6 \%$, respectively). However, there were a statistically greater percentage of patients with moderate anemia as compared to mild anemia who received further diagnostic evaluation to investigate the cause of their anemia (62.7\% compared to $41.5 \%$, respectively $(\mathrm{P}<0.05))$. Specifically, our results show that providers tend to conduct serum iron studies more frequently in patients with moderate anemia. However, other non-invasive studies for anemia including folic acid, cobalamin, fecal occult blood, reticulocytes, and protein electrophoresis were not commonly performed on patients and had no significant difference in the frequency in which these tests

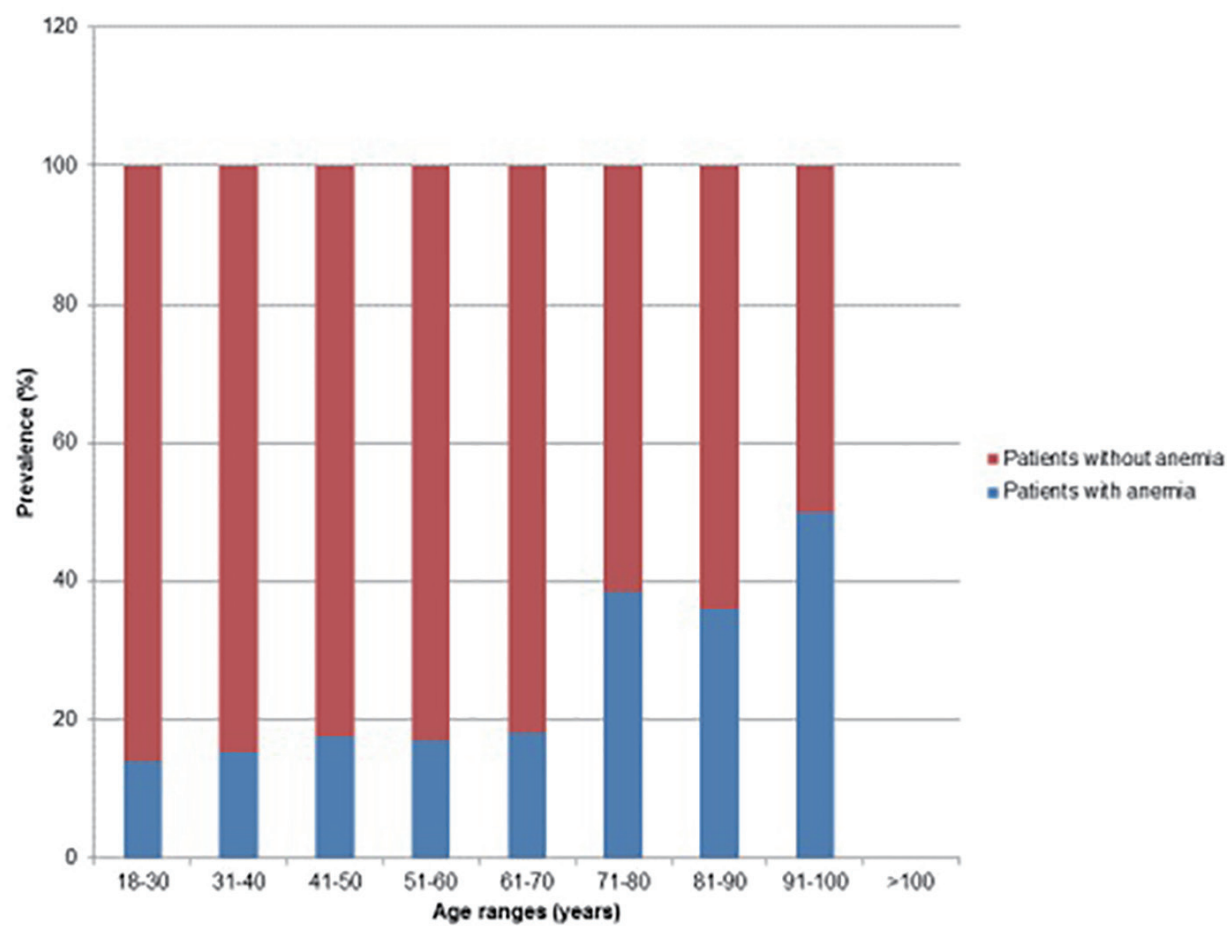

Figure 1. Prevalence of anemia with respect to age. 


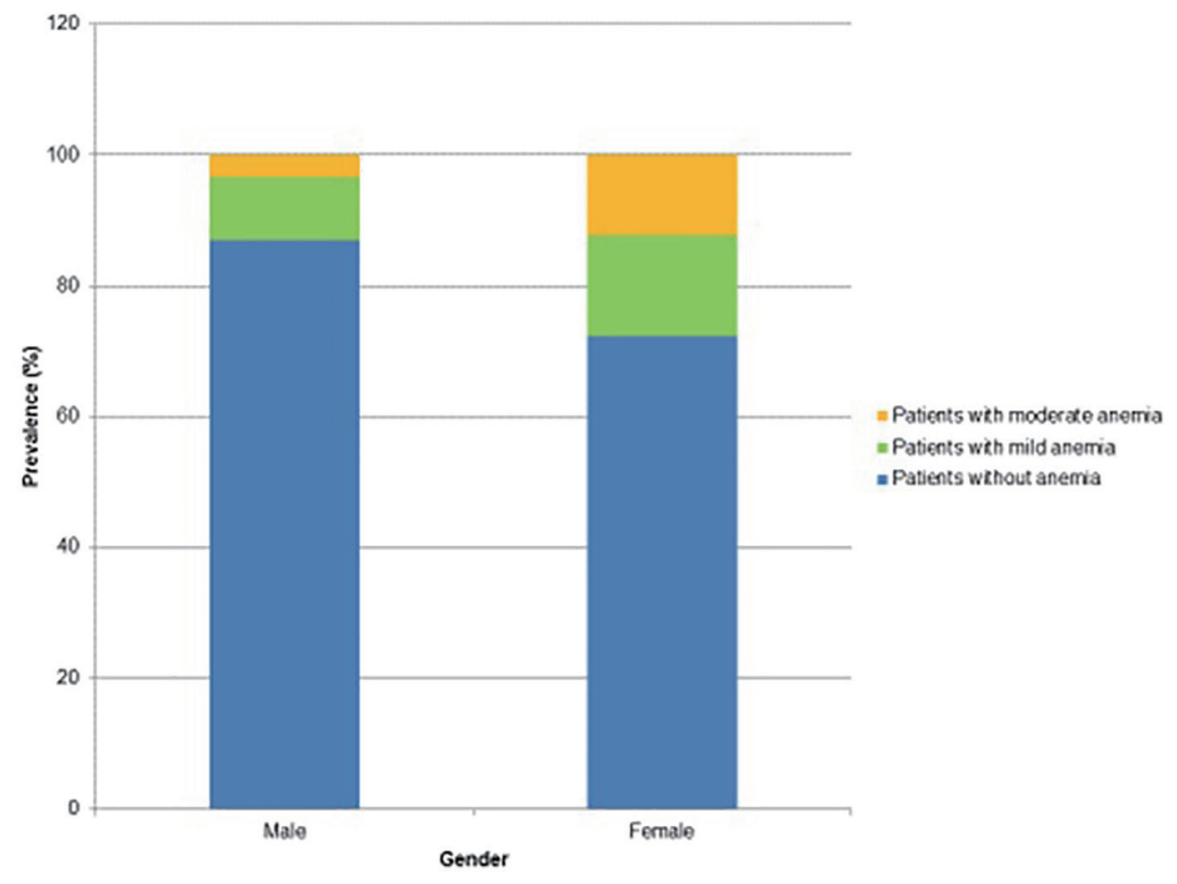

Figure 2. Prevalence and severity of anemia in males compared to females.

were conducted when comparing the mild and moderate anemia groups (Tables 4 and 5, Fig. 6). There were $14.8 \%$ of anemic patients who had resolution of anemia without therapy in 1 year. Additionally, $15.7 \%$ of patients were on iron replacement therapy, and $6.5 \%$ were on cobalamin therapy. Fewer patients in the mild anemia group underwent further laboratory investigation for anemia compared to the patients in the moderate anemia group (Table 6). No specific etiology
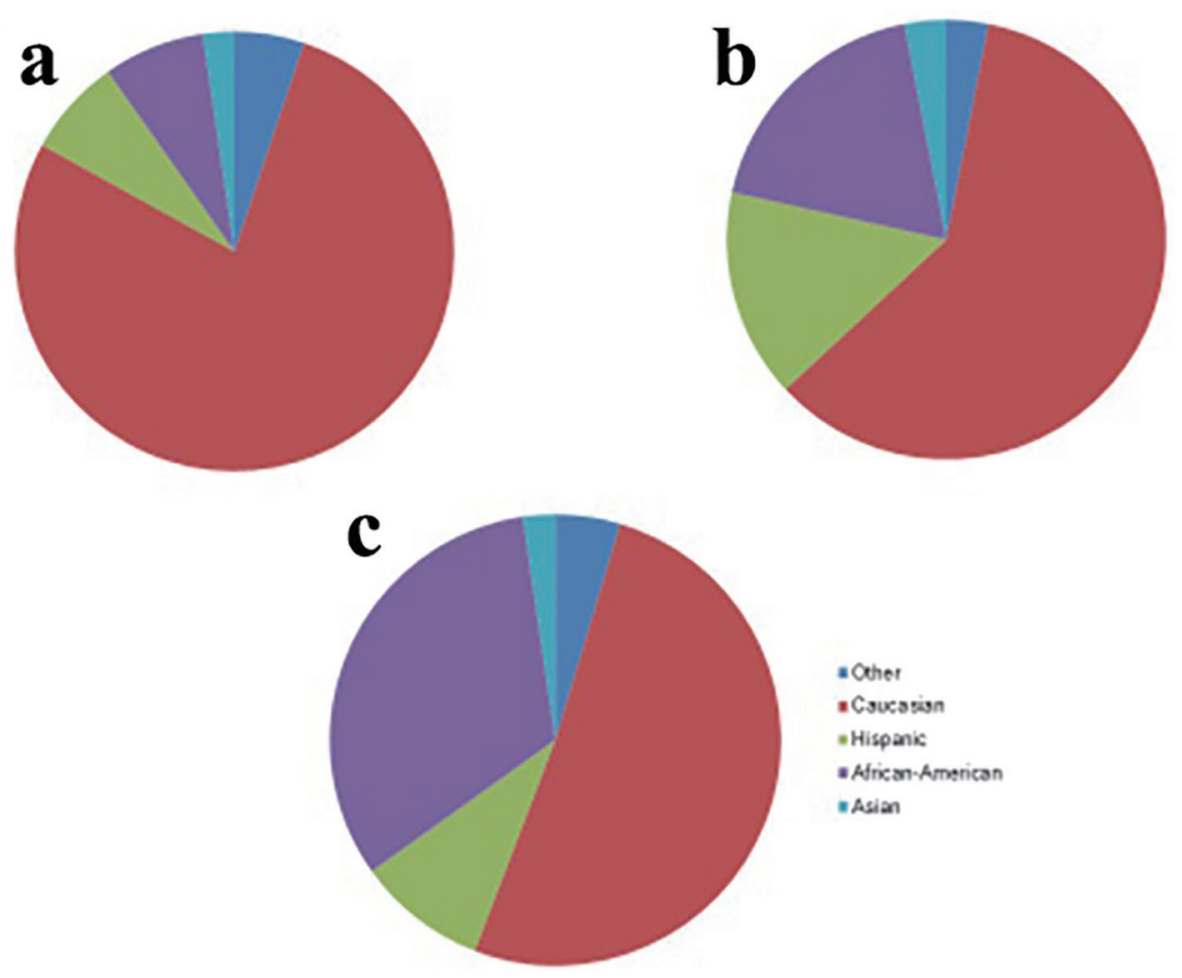

Figure 3. Comparison of racial distributions in patients without anemia (a), mild anemia (b), and moderate anemia (c). 


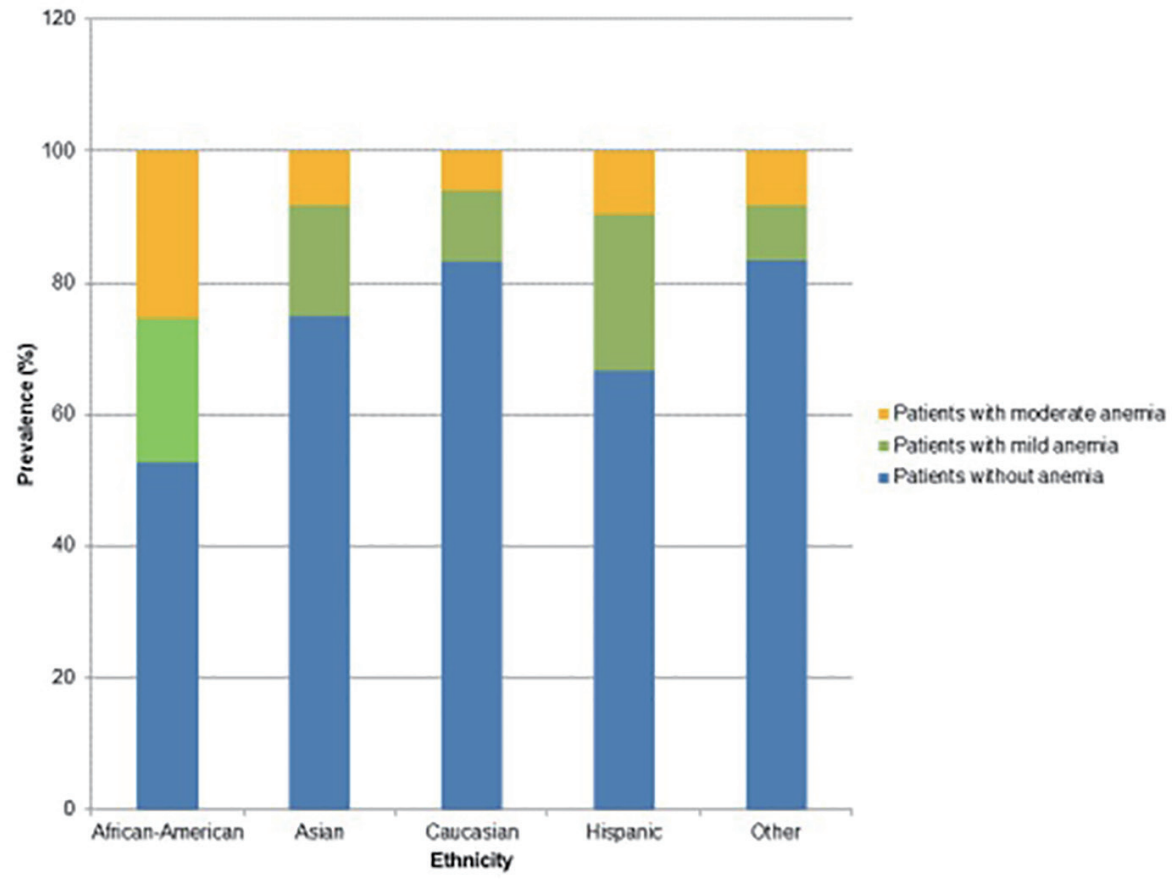

Figure 4. Prevalence and severity of anemia with respect to ethnicity.

of anemia was found in $24 \%$ of patients.

\section{Discussion}

Our study demonstrated three important findings: increasing age was associated with increased prevalence of anemia; females, African-American race and Hispanic race were at higher risk for having anemia; and the presence of one or more comorbidities (such as essential hypertension, hypothyroidism, CKD, malignancy, rheumatologic disease, CHF, and coronary artery disease) was associated with a higher prevalence of anemia compared to

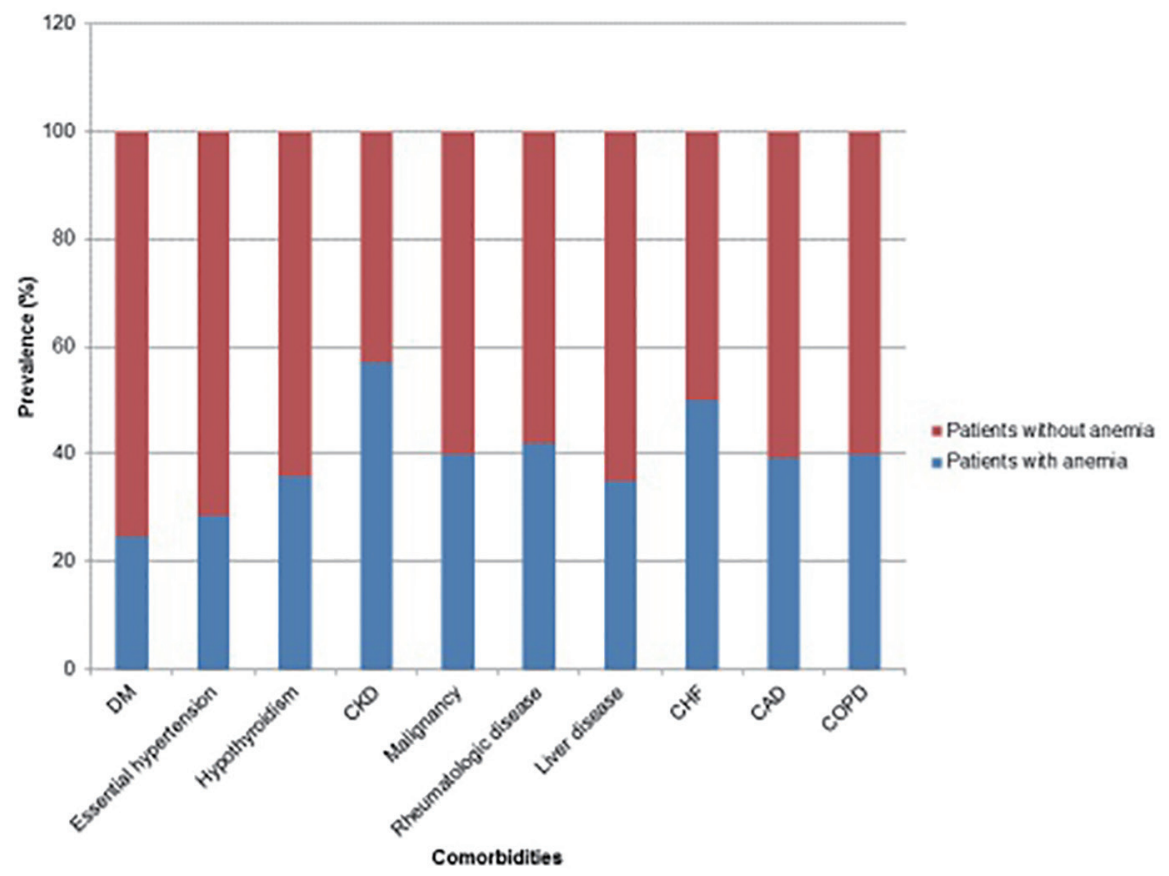

Figure 5. Prevalence of anemia with respect to comorbidities. 


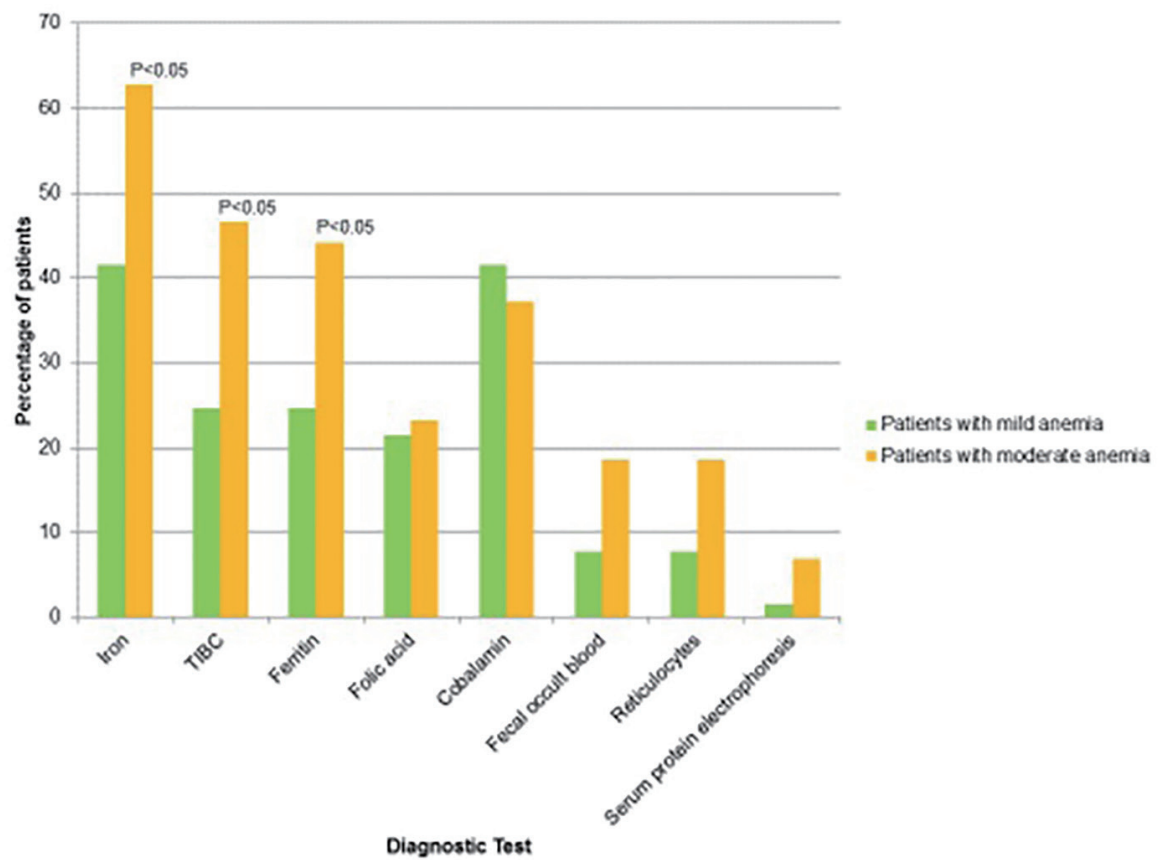

Figure 6. Comparison of patients with mild versus moderate anemia who received further diagnostic testing.

the patients without these factors. Furthermore, our results also show that patients with a greater severity of anemia underwent further diagnostic tests to investigate the cause.

Multiple studies have been conducted to determine the prevalence of anemia in adults, with special interest in the elderly population. For example, an investigation by Guralnik et al showed that $11 \%$ of men and $10.2 \%$ of women greater than the age of 65 had anemia [1]. However, another study conducted by Izaks et al showed that $17 \%$ of men and $28 \%$ of women greater than the age of 85 had anemia [14]. Other similar studies showed that the prevalence of anemia appeared to decrease in younger populations $(<60$ years of age) $[15,16]$. Since anemia is multifactorial, there have been efforts to understand the significance of anemia amongst the elderly population. Several investigations have shown that the presence of anemia may be a risk factor for falls that result in fractures [17-19], cognitive dysfunction [20, 21], complications during hospitalizations [22], and morbidity and mortality in the elderly [14]. There are many theories which seek to explain the growing prevalence of anemia in the elderly, which include inappropriate response to erythropoietin [23], agerelated increases in the secretion of pro-inflammatory cytokines, or the propensity of bone marrow failure with increasing age [24]. Our study is congruent with the previous findings that the prevalence of anemia is associated with increasing age.

Our study demonstrates that the prevalence of anemia varies by ethnicity, notably with a greater prevalence of anemia in African-Americans and Hispanics. These findings have also been observed in prior investigations. The Third National Health and Nutrition Examination Survey (NHANESIII) showed that a greater percentage of non-Hispanic AfricanAmerican patients had anemia as compared to Caucasian patients over the age of $65[1,25]$. Additionally, another study by $\mathrm{Wu}$ et al also showed a greater prevalence of anemia in African-Americans in populations less than 60 years of age [26]. One cross-sectional study published by Zakai et al in 2009 sought to investigate the cause of such racial disparities in the

Table 6. Percentage of Patients That Underwent Further Laboratory Investigation for Anemia

\begin{tabular}{llll}
\hline & Patients with mild anemia $(\mathbf{N}=\mathbf{6 5}), \mathbf{\%}$ & Patients with moderate anemia $(\mathbf{N}=\mathbf{4 3}), \mathbf{\%}$ & P value \\
\hline Iron & 41.5 & 62.8 & 0.0314 \\
Total iron binding capacity (TIBC) & 24.6 & 46.5 & 0.0187 \\
Ferritin & 24.6 & 44.1 & 0.0342 \\
Folic acid & 21.5 & 23.2 & 0.8343 \\
Cobalamin & 41.5 & 37.2 & 0.6543 \\
Fecal occult blood & 7.7 & 18.6 & 0.0895 \\
Reticulocytes & 7.7 & 18.6 & 0.0895 \\
Serum protein electrophoresis & 1.5 & 6.9 & 0.1448 \\
\hline
\end{tabular}


prevalence of anemia. Interestingly, demographic factors that were associated with a higher risk of having anemia included lower socioeconomic status, chronic inflammation, vascular disease, diabetes, hypertension, and microcytosis [15, 27].

These demographic differences in the prevalence of anemia have sparked further investigation into the impacts of anemia on chronic disease. Several studies have shown a clear relationship between anemia and its effects on pre-existing cardiovascular disease. Silverberg and colleagues found that there was higher 30-day mortality in elderly patients with anemia who were hospitalized with acute myocardial infarction [28]. Furthermore, the ELITE II trial and other investigations have shown that anemia is an independent risk factor for leftventricular hypertrophy and diastolic dysfunction as well as morbidity and mortality in patients with CHF [29-31]. Moreover, anemia in patients with COPD has been shown to be correlated with increased healthcare utilization and hospitalizations, decreased quality of life, and decreased survival compared to patients with COPD who are not anemic [31, 32].

In addition to cardiopulmonary and vascular disease, anemia may also have prognostic implications in rheumatologic disease and malignancy. Correction of anemia secondary to chronic inflammation with intravenous iron or erythrocyte stimulating agents (ESAs) in patients with rheumatoid arthritis led to improved muscle strength, decreased levels of fatigue, and reduction in disease activity [32]. Glaspy et al also demonstrated that patients with non-myeloid malignancies who were treated with ESAs had improved functional status and quality of life with decreased transfusion requirements [33].

While there have been many studies investigating the demographic differences and impact of anemia on overall morbidity, to our knowledge, our study is the first to demonstrate a relationship between the severity of anemia and the frequency that further diagnostic evaluation is undertaken. We found that providers conducted serum iron studies more frequently in patients with moderate anemia compared to mild anemia, but other noninvasive tests including folic acid, cobalamin, fecal occult blood, reticulocytes, and protein electrophoresis were not commonly performed. Further studies should be aimed at determining if earlier diagnostic evaluation for anemia affects outcome in terms of time to intervention, morbidity, mortality, and quality of life.

The major strengths of our study include its large sample size and one office location. However, our study had several limitations, including retrospective analysis, and data regarding patients' medical and family histories that were based solely on documentation.

We conclude that the prevalence of anemia increases with increasing age, female gender, African-American and Hispanic race, and comorbidities, such essential hypertension, hypothyroidism, CKD, malignancy, rheumatologic disease, CHF, and coronary artery disease. Furthermore, patients with more severe anemia are more likely to undergo further diagnostic evaluation to investigate the cause of anemia.

\section{Acknowledgments}

The authors thank Christine Rickette RN (study coordinator) of for her contribution to this study.

\section{Grant Support}

None.

\section{Conflict of Interest}

None.

\section{References}

1. Guralnik JM, Eisenstaedt RS, Ferrucci L, Klein HG, Woodman RC. Prevalence of anemia in persons 65 years and older in the United States: evidence for a high rate of unexplained anemia. Blood. 2004;104(8):2263-2268.

2. Smith D. Management and treatment of anemia in the elderly. Clin Geriatr. 2002;10:47-53.

3. Tilly-Gentric A, Malo JP, Marion V. Primary myelodysplasia: management and outcome at 3 years in 45 patients age 65 and older. J Am Geriatr Soc. 2001;49(10):13581360 .

4. Artz AS, Fergusson D, Drinka PJ, Gerald M, Bidenbender R, Lechich A, Silverstone F, et al. Mechanisms of unexplained anemia in the nursing home. J Am Geriatr Soc. 2004;52(3):423-427.

5. Culleton BF, Manns BJ, Zhang J, Tonelli M, Klarenbach $\mathrm{S}$, Hemmelgarn BR. Impact of anemia on hospitalization and mortality in older adults. Blood. 2006;107(10):38413846.

6. Vlagopoulos PT, Tighiouart H, Weiner DE, Griffith J, Pettitt D, Salem DN, Levey AS, et al. Anemia as a risk factor for cardiovascular disease and all-cause mortality in diabetes: the impact of chronic kidney disease. J Am Soc Nephrol. 2005;16(11):3403-3410.

7. Go AS, Yang J, Ackerson LM, Lepper K, Robbins S, Massie BM, Shlipak MG. Hemoglobin level, chronic kidney disease, and the risks of death and hospitalization in adults with chronic heart failure: the Anemia in Chronic Heart Failure: Outcomes and Resource Utilization (ANCHOR) Study. Circulation. 2006;113(23):2713-2723.

8. Kalra PR, Bolger AP, Francis DP, Genth-Zotz S, Sharma R, Ponikowski PP, Poole-Wilson PA, et al. Effect of anemia on exercise tolerance in chronic heart failure in men. Am J Cardiol. 2003;91(7):888-891.

9. Yohannes AM, Ershler WB. Anemia in COPD: a systematic review of the prevalence, quality of life, and mortality. Respir Care. 2011;56(5):644-652.

10. Hebert PC, Yetisir E, Martin C, Blajchman MA, Wells $\mathrm{G}$, Marshall J, Tweeddale M, et al. Is a low transfusion threshold safe in critically ill patients with cardiovascular diseases? Crit Care Med. 2001;29(2):227-234.

11. Kulier A, Levin J, Moser R, Rumpold-Seitlinger G, Tudor IC, Snyder-Ramos SA, Moehnle P, et al. Impact of preoperative anemia on outcome in patients undergo- 
ing coronary artery bypass graft surgery. Circulation. 2007;116(5):471-479.

12. Patel KV. Epidemiology of anemia in older adults. Semin Hematol. 2008;45(4):210-217.

13. Le CH. The prevalence of anemia and moderate-severe anemia in the US population (NHANES 2003-2012). PLoS One. 2016;11(11):e0166635.

14. Izaks GJ, Westendorp RG, Knook DL. The definition of anemia in older persons. JAMA. 1999;281(18):1714-1717.

15. Penninx BW, Pahor M, Cesari M, Corsi AM, Woodman RC, Bandinelli S, Guralnik JM, et al. Anemia is associated with disability and decreased physical performance and muscle strength in the elderly. J Am Geriatr Soc. 2004;52(5):719-724.

16. Fleming DJ, Jacques PF, Tucker KL, Massaro JM, D'Agostino RB, Sr., Wilson PW, Wood RJ. Iron status of the free-living, elderly Framingham Heart Study cohort: an iron-replete population with a high prevalence of elevated iron stores. Am J Clin Nutr. 2001;73(3):638-646.

17. Dharmarajan TS. Anemia and response to epoetin alfa: the cause of anemia matters! J Am Geriatr Soc. 2008;56(8):1574-1575.

18. Guse CE, Porinsky R. Risk factors associated with hospitalization for unintentional falls: Wisconsin hospital discharge data for patients aged 65 and over. WMJ. 2003;102(4):37-42.

19. Dharmarajan TS, Norkus EP. Mild anemia and the risk of falls in older adults from nursing homes and the community. J Am Med Dir Assoc. 2004;5(6):395-400.

20. Argyriadou S, Vlachonikolis I, Melisopoulou H, Katachanakis $\mathrm{K}$, Lionis $\mathrm{C}$. In what extent anemia coexists with cognitive impairment in elderly: a cross-sectional study in Greece. BMC Fam Pract. 2001;2:5.

21. Chaves PH, Carlson MC, Fried LP. Cognitive function in high functioning older women: does hemoglobin concentration matter. J Am Geriatr Soc. 2002;50(4):S149-S150.

22. Myers E, O'Grady P, Dolan AM. The influence of preclinical anaemia on outcome following total hip replacement. Arch Orthop Trauma Surg. 2004;124(10):699-701.

23. Kario K, Matsuo T, Kodama K, Nakao K, Asada R. Reduced erythropoietin secretion in senile anemia. Am J He- matol. 1992;41(4):252-257.

24. Balducci L. Anemia, cancer, and aging. Cancer Control. 2003;10(6):478-486.

25. Beutler E, West C. Hematologic differences between African-Americans and whites: the roles of iron deficiency and alpha-thalassemia on hemoglobin levels and mean corpuscular volume. Blood. 2005;106(2):740-745.

26. Wu WC, Rathore SS, Wang Y, Radford MJ, Krumholz HM. Blood transfusion in elderly patients with acute myocardial infarction. N Engl J Med. 2001;345(17):12301236.

27. Zakai NA, McClure LA, Prineas R, Howard G, McClellan W, Holmes CE, Newsome BB, et al. Correlates of anemia in American blacks and whites: the REGARDS Renal Ancillary Study. Am J Epidemiol. 2009;169(3):355-364.

28. Silverberg DS, Wexler D, Iaina A. The role of anemia in the progression of congestive heart failure. Is there a place for erythropoietin and intravenous iron? J Nephrol. 2004;17(6):749-761.

29. Nair D, Shlipak MG, Angeja B, Liu HH, Schiller NB, Whooley MA. Association of anemia with diastolic dysfunction among patients with coronary artery disease in the Heart and Soul Study. Am J Cardiol. 2005;95(3):332336.

30. Sharma R, Francis DP, Pitt B, Poole-Wilson PA, Coats AJ, Anker SD. Haemoglobin predicts survival in patients with chronic heart failure: a substudy of the ELITE II trial. Eur Heart J. 2004;25(12):1021-1028.

31. Sarkar M, Rajta PN, Khatana J. Anemia in Chronic obstructive pulmonary disease: Prevalence, pathogenesis, and potential impact. Lung India. 2015;32(2):142-151.

32. Kaltwasser JP, Kessler U, Gottschalk R, Stucki G, Moller B. Effect of recombinant human erythropoietin and intravenous iron on anemia and disease activity in rheumatoid arthritis. J Rheumatol. 2001;28(11):2430-2436.

33. Glaspy J, Bukowski R, Steinberg D, Taylor C, Tchekmedyian S, Vadhan-Raj S. Impact of therapy with epoetin alfa on clinical outcomes in patients with nonmyeloid malignancies during cancer chemotherapy in community oncology practice. Procrit Study Group. J Clin Oncol. 1997;15(3):1218-1234. 